\title{
Distopia e religião em perspectiva tillichiana
}

\author{
Joe Marçal G. Santos*
}

\begin{abstract}
RESUMO
A distopia consolidou-se como gênero narrativo no decorrer do século $\mathrm{XX}$ tanto na literatura quanto no cinema a partir de uma pretensão crítica à modernidade. Em contraste com a tradição literária iniciada pelo humanista inglês Tomas Morus, em Utopia (1516), a narrativa distópica desloca a ideia de não-lugar implicado no neologismo utopia da referência espacial e a situa em um tempo futuro, no qual o potencial destrutivo do presente é efetivado dramaticamente. $\mathrm{O}$ que nos interessa é a recorrência do tema religioso nesse conjunto de obras, para o que nos propomos delinear categorias analíticas em diálogo com a teologia da cultura.
\end{abstract}

Palavras-chave: Literatura; Cinema; Diegese; História; Demônico.

\section{DYSTOPIA AND RELIGION ACCORDING TO A TILLICHIAN PERSPECTIVE}

\begin{abstract}
:
Dystopia emerged as a narrative genre in the course of the 20th century, both in literature and in cinema, based on a critical purpose to modernity. In contrast to the literary tradition started by the humanist Tomas Morus, in Utopia (1516), dystopic narrative displaces the idea of non-place implied in the utopia neologism from the spatial reference and places it in a future time, in which the destructive potential of the present is dramatically actualized. What interests us is the recurrence of the religious theme in this set of narrative works, for which we propose to outline analytical categories in dialogue with the theology of culture.
\end{abstract} Keywords: Literature; Cinema; Diegesis; History; Demonic.

* Doutor em Teologia (São Leopoldo, EST, 2006), professor adjunto do Núcleo de Ciências da Religião da Universidade Federal de Sergipe. E-mail: jmgsantos@academico.ufs.br. Acesso Lattes: http://lattes.cnpq.br/5359207133765624. 


\section{Introdução}

A análise da noção de utopia e de seu papel na formação tanto intelectual quanto artística da modernidade nos impele labirinto adentro de sentidos e usos da noção de cultura, lançando luz sobre o lugar que esta última ocupa em meio às representações sociais que forjam a ideia de modernidade como um projeto de sociedade. Despojada, aparentemente, de suas raízes mítico-religiosas, na filosofia moral e política, bem como na imaginação literária moderna, a ideia de utopia não esconde suas feições escatológicas e redentivas. Como seu duplo e, ao mesmo tempo, sua negação, a distopia irrompe no século XX cobrando certas contradições da cultura moderna, ainda que tomando parte nela mesma. Na problematização que nos interessa aqui, nossa hipótese é tomar a utopia, em sentido tanto reflexivo quanto narrativo, como chave hermenêutica crítica para uma análise da relação entre religião e modernidade a partir da literatura e do cinema.

É importante lembrar que o termo utopia nasce na condição de neologismo, na pena do inglês Thomas More (latinizado Tomas Morus), em 1516, como título de uma narrativa ficcional em forma de relato de viagem, que sintetizava estilística e reflexivamente o ideal de autonomia intelectual da "república literária erasmiana" (YORAN, 2010). Sob esse aspecto, é determinante o fato de Morus valer-se de um relato de viagem: o mesmo se instituía então, em meio a prática epistolar, como gênero textual ao calor das grandes navegações, para criar uma narrativa ficcional acerca de uma sociedade que realizara o sonho republicano humanista. À ilha desconhecida, Morus nomeou Utopia; a narração de Morus é em primeira pessoa, na qual discorre sobre o relato que ouvira de Rafael Hitlodeu, personagem viajante desbravador que chegara à ilha após desembarcar de um navio capitaneado por Américo Vespúcio. Por meio do relato de Hitlodeu, Morus descreve Utopia como topos crítico que espelha seu inconformismo político, social e antropológico, valendo-se tanto das aspirações do humanismo erasmiano quanto do retorno às fontes da idealização mítica e clássica greco-latina e judaico-cristã acerca de uma sociedade ideal.

Nesses termos, uma dupla e ambígua natureza está presente desde o berço dessa palavra: recorrendo ao termo grego topos (lugar), Morus lhe acrescenta o prefixo de negação ov para imaginar uma idealização 
moral, política e intelectual, isto é, um não-lugar de caráter narrativo-ficcional. Ao mesmo tempo, lhe imprime um profundo apelo antropológico e psicológico em relação a um "bom lugar" desejado para se viver. A imagem carrega uma tensão crítica de cunho moral-filosófico ${ }^{1}$, mas não é uma novidade em si mesma. Ela remete a uma espécie de arquétipo, mas cuja forma narrativa morusiana acaba resultando na novidade do gênero literário a que chamamos até hoje de literatura utópica. Nesse processo, porém, o termo sofre uma naturalização (nomeadamente, um deneologização), cumprindo um papel determinante na formação do ideário moderno enquanto projeto de sociedade; um processo no qual o significado de utopia, contudo, jamais foi unívoco.

Desse quadro geral, destaco ao menos duas questões para atentarmos. Primeiro, quanto às implicações da dupla natureza do termo, que é tanto ficcional quanto crítico-moral: é nessa dimensão que perceberemos aspectos decisivos da antropologia em que se baseia a obra de Morus. A segunda questão, trata da novidade formal da utopia enquanto gênero narrativo literário, sua reelaboração positiva e pedagógica no sentido moderno-iluminista e o que resulta disso, já no quadro da cultura contemporânea, como uma "virada distópica da utopia", expressa especialmente por meio da literatura e do cinema.

\section{De Utopia, de T. Morus, às utopias e distopias contemporâneas}

Se a prática da forma literária coincide com o surgimento de culturas agrárias que, fixadas em territórios, passam a ter de lidar com o problema da vida na polis, não é de estranhar a profusão de literaturas que tomam determinados topos (lugares/cidades) como símbolos das angústias e possibilidades de uma boa vida em sentido moral e político. Entre o Jardim do Éden e Sodoma e Gomorra, entre a Babilônia e a Nova Jerusalém, entre a caverna de Platão e a Cidade de Deus de Agostinho, não faltaram referências mítico-religiosas para Tomas Morus engendrar sua ilha utópica. Por sua vez, a novidade de sua criação, segundo Fátima Vieira (2010), decorre de uma tensão resultante de três características elementares da ilha ficcionalizada pelo humanista:

1 Característica que contrasta sintomaticamente com os traços pedagógicos da recepção iluminista do humanismo, a qual, como veremos adiante, coloca a ideia de utopia em bases mais positivas do que crítico-negativas. 
Primeiro, trata-se de um não-lugar apenas por que inacessível, isolado, separado do mundo conhecido - qualidade que, no início do século XVI, sob o impacto das narrativas das grandes navegações, sugeria expectativas de ser uma realidade. Ou seja, a narrativa deixa a imagem ficcional da ilha aberta à plausibilidade do real: para o/a leitora de Morus, a ilha Utopia poderia ser um não-lugar por que não localizada, e não necessariamente por ser produto de imaginação literária.

Segundo, em contraste com Platão e Agostinho, e mesmo sugerindo uma superação a estes, a república de Utopia não é apenas um esboço (como em Platão) ou objeto de fé em um outro-topos (como em Agostinho), mas é relatada como uma realização, ainda que não localizada - isto é, no acontecimento da leitura, ela se torna uma possibilidade para o aqui e agora.

Terceiro, ao final do relato, uma variação do neologismo recorre ao prefixo $\varepsilon v$ em lugar de ov introduzindo a visão dos habitantes de Utopia a respeito de sua própria sociedade: em função de tão perfeitas leis e da vida tão boa, seus habitantes sugerem que a ilha deveria ser chamada de Eutopia (o bom lugar) em vez de Utopia - isto é, na narrativa de Morus, o não-lugar se realiza como bom-lugar para quem nele está, a despeito de sua não-localização. Se a pronúncia inglesa de ambas as palavras (utopia e eutopia) é a mesma, tal ambiguidade, e o paradoxo de um "já agora, ainda não" que ela esboça, torna o argumento ainda mais sugestivo.

Com efeito, é a partir desse potencial simbólico e diegético que a obra morusiana irá abrir caminhos para o neologismo se sedimentar e repercutir em meio a muitas disputas semânticas; mas que, de todo modo, parece-nos razoável defini-lo a partir de seu potencial crítico, nos seguintes termos:

(...) desejo de uma vida melhor, causado por um sentimento de descontentamento com a sociedade em que se vive (a utopia passa a ser vista como uma questão de atitude). Esta última característica é sem dúvida a mais importante, pois permite incluir no quadro da utopia uma vasta gama de textos informados pelo que Ernst Bloch considerou a principal energia da utopia: a esperança. A utopia deve então ser vista como uma questão de atitude, como uma espécie de reação a um presente indesejável e uma aspiração de superar todas as dificuldades pela imaginação de alternativas possíveis (VIEIRA, 2010, p. 6-7 - tradução nossa, grifo nosso). 
Contudo, embora conserve o aspecto elementar subjetivo de compreendê-la como atitude e disposição crítica-criativa frente à dialética de estranhamento e esperança na relação entre a realidade dada e o não/ bom -lugar, desde a qual Morus opera sua narrativa, tal definição difere da narrativa germinal ao encetar um deslocamento da referência espacial para a temporal (reação a um presente indesejável), o que ocorre especialmente em torno da apropriação positivista da noção de utopia, situando-a no campo simbólico da imaginação histórica² ${ }^{2}$ Nesse sentido, é importante ressaltar que o relato de viagem à ilha, na narrativa de Morus, não trata da história, do processo que permitiu a realização da república utópica - referências ao passado são modestas e sempre no sentido de uma realidade que fora superada. Isto é, mais do que indicar um processo, o relato apresenta um estado de coisas realizado e bem-sucedido, destacando, em todas suas esferas, as qualidades morais e espirituais da mesma. Ou seja, trata-se de uma referência crítico-política estática, para a qual a dimensão processual histórica figura em segundo plano (VIEIRA, 2010; YORAN, 2010; HILÁRIO, 2013).

Vê-se isso, de forma especial, no capítulo que encerra o relato, que trata das religiões dos utupienses: o relato destila as qualidades morais e políticas das religiões praticadas em Utopia sob o imperativo da tolerância religiosa, que inclui a prática de um proselitismo baseado na persuasão "racional, discreta e moderada" (MORUS, 2013, p. 115). Nessas bases, Morus relata de um grande número de habitantes ter abraçado a fé cristã, harmonizando-a com a religião que então predominava em torno do culto à Mitra ${ }^{3}$. O destaque fica por conta do papel do rei Utopos, como o grande-líder, mentor do código legal e, ao mesmo tempo, juiz, na construção dessas relações de tolerância, trazendo à

2 Dimensão na qual a modernidade lançará, em associação à ciência e à técnica, toda sua expectativa de autorrealização, o que foi expresso sintomaticamente pelo francês Charles Renouvier, em sua novela Uchronie, de 1876. No campo dos Utopian Studies, esse correlato define traços diegéticos, em particular, da distopia, como veremos adiante.

3 Um expressivo indicador da perspectiva humanista de Morus, a referência à antiga religião persa remete aos processos divinatórios da Antiguidade Greco-Latina, que prefigura uma orientação cúltica de apelo monolátrico, e que repercutirá na síntese simbólica cristã realizada em sua conformação clássica a partir do séc. IV. Os editores da tradução crítica que usamos remetem aqui à provável leitura morusiana de Picco della Mirandola (MORUS, 2004, p. 113, nota 66). 
tona uma faceta do passado que fora superado mediante a imposição de regras adequadas à exigência moral:

Antes de chegar à ilha, o rei Utopos tinha conhecimento de que seus habitantes lutavam continuamente entre si por questões religiosas. De fato, concluiu que seria fácil conquistar a ilha porque as diferentes seitas estavam demasiadamente ocupadas, lutando umas contra outras, para se oporem às suas forças. Portanto, tão logo conquistou a vitória, decretou que cada um era livre para professar a religião de sua própria escolha (...) (MORUS, 2004, p. 116)

Em contraste, o ateísmo não é tolerado na ilha. Sem a crença básica na providência divina e na imortalidade da alma, os indivíduos negariam "a sublimidade de sua própria alma" e reduziriam a si mesmos "à condição do animal que possui apenas seu corpo material perecível" - e conclui: "iriam trair e desrespeitar as leis e os costumes da sociedade se não fossem contidos pelo medo" (MORUS, 2004, p. 116). Trata-se, como se vê, de um problema moral em sentido pragmático.

Em seu prefácio à edição crítica de Utopia, João Almino pormenoriza o relato de Thomas More, apresentando o regime modelar da ilha como um império, destacando suas estratégias de dominação, colonização e expansão nas relações com outros povos. Na prática, a ilha realiza de forma modelar o que, no início do século XVI, a Inglaterra pretendia, mas nem de longe conseguia realizar; mais do que prescrever um modelo, segundo Almino, interessa a Morus lançar sua crítica:

Agindo segundo a razão, e mesmo sem conhecer o cristianismo, os utopienses vivem melhor do que os europeus e foram capazes de construir instituições que merecem respeito e admiração, enquanto os povos cristãos não conseguem pôr em prática as virtudes consagradas por sua religião e se destroem uns aos outros. Os utopienses comportam-se, no fundo, como se fossem verdadeiros cristãos; fazem o que os europeus deveriam fazer, se seguissem seus próprios preceitos cristãos (ALMINO, 2004, p. XI).

Para nosso enfoque, é digno de nota o papel que a religião desempenha aqui, vinculado à bem-sucedida estratégia de dominação e organização da sociedade utopiense. Ela media a realização da Utopia, que se dá por meio da mobilização moral-religiosa dos indivíduos, não de uma ação histórica, em termos modernos. De todo modo, é uma 
religião submetida a um regime de prerrogativa moral - como relata Morus (2004, p. 114-115), a respeito de um convertido ao cristianismo que passou a pregar "a fé cristã com mais zelo do que discrição" e acabou sendo condenado à prisão "não por ter desprezado sua religião, mas por provocar desordem pública". Trata-se, portanto, de uma teologia muito prática e determinada à regulação moral, ao modo da religio licita romana e prefiguração da "religião civil" rousseana, cuja finalidade é expressamente orientada pelos interesses de manutenção de uma ordem e estratos sociais vigentes. Destacamos este aspecto em função do potencial totalitário que pesa sobre a religião da república de Utopia, que repercutirá nas inflexões críticas ao pensamento e literatura utópica e dará lugar ao objeto de nosso interesse, a relação entre religião e distopia.

\section{Distopia e religião a partir da crítica tillichiana à noção de utopia}

É no iluminismo, à luz da noção de história como processo humano autodirigido, que o pensamento e a imaginação utópica são colocados em novas bases, vinculando a metafísica positiva da ordem utópica à noção de tempo e história determinados pelos símbolos da evolução e do progresso. Nessa perspectiva, a "disposição utópica” está no DNA da modernidade (a própria noção de cultura, seja como civilisation ou como kultur, dar-se-á às voltas disso), presente como uma orientação de realização de sentido - para usarmos de uma fórmula tillichiana - em diversas esferas, processos e criações culturais, seja na ciência e na tecnologia, na política e na educação, como também na religião e na arte.

Quando Tillich, no terceiro volume da Teologia Sistemática, faz sua crítica à qualidade quase-religiosa da noção de progresso na cultura europeia do XIX, ele identifica a função orientadora de caráter incondicional que o pensamento e a imaginação utópica cumprem naquele contexto. Após sua análise das ambiguidades da vida sob a dimensão histórica, donde emergem as perguntas pelo sentido existencial da história, Tillich volta sua análise ao tema da utopia como uma interpretação da história que, contudo, implica numa positividade inadequada à pergunta pelo sentido da história. Na esteira da interpretação científico-mecanicista da história que modela a cultura moderna, em cujas 
características Tillich destaca sua valorização da dimensão temporal como processo em que as coisas e a vida ocorrem sem oferecer "uma contribuição especial à interpretação da existência como tal" (2005, p. 786), a ideia de progresso se estabeleceu, segundo sua análise, como uma resposta positiva a uma interpretação existencial da história. Daí que o progresso, embora seja uma qualidade intrínseca à cultura científico-tecnológico-industrial, acaba se revestindo de um poder simbólico "tão grande como o dos grandes símbolos religiosos de interpretação histórica, incluindo o símbolo do Reino de Deus" (TILLICH, 2005, p. 786), do que resulta seu significado quase-religioso, ainda que com uma teleologia intra-histórica - escancarando, segundo o mesmo, a fonte do problema.

Nesses termos, Tillich aponta duas formas de progressismos no contexto histórico-cultural que compreende os séculos XIX e XX: a primeira, seria o progressismo propriamente dito, de orientação idealista e neokantista, desde o qual "a realidade é a criação jamais concluída da atividade cultural do ser humano" (2005, p. 787)4. A segunda forma de progressismo sob a crítica de Tillich, por sua vez, é o que ele define como utopismo, que objetiva o progresso em um "alvo definido: a chegada àquele estágio da vida em que se superam as ambiguidades da vida" (2005, p. 787). Nesse ponto, Tillich ressalva a necessidade de não confundir "ímpeto utópico e o símbolo da utopia interpretado literalmente": o primeiro, ele define como "crença de que a ação revolucionária presente trará a transformação final da realidade, o estágio da história em que o ou topos (o não-lugar) se tornará o lugar universal" (2005, p. 788), sugerindo a dívida secularizada desta tradição de pensamento utópico-político para com ideais utópico-religiosos renascentistas, sob o corolário da esperança.

4 "Although they are part of the background of the concept of utopia, Plato's Republic, and St Augustine's The City of God differ from More's Utopia, as Plato does not go beyond mere speculation about the best organization of a city, and St Augustine projects his ideal into the afterlife (thus creating not a utopia but an alotopia )" (VIEIRA, 2010, p. 6). A tensão mencionada pela autora aponta para o que a tradição teológica luterana afirmará com respeito ao Reino de Deus, como uma realidade "já agora-ainda não", a qual Tillich remete nas "características do símbolo Reino de Deus" como sua qualidade de imanência transcendente, TS, p. 790-93. 
Em sua radicalidade, o foco do problema seria que o utopismo se baseia na desconsideração da "sempre presente alienação existencial e as inevitáveis ambiguidades da vida e da história" (TILLICH, 2005, p. 788). Esta desconsideração, seguindo o raciocínio do autor, está implicada na reivindicação idolátrica ${ }^{5}$ de uma situação histórica futura como realização última e absoluta do sentido da história - uma reivindicação que está na base, no entender de Tillich, de toda a tradição utópica. Mas o século XX revelou "uma completa ambiguidade entre progresso e recaída naqueles âmbitos em que está envolvida a liberdade humana" (TILLICH, 2005, p. 788), resultando na história de desapontamentos, indiferenças e desesperança "que sempre se segue a qualquer confiança idolátrica em algo finito” (TILLICH, 2005, p. 788) ${ }^{6}$. Daí ser inadequada e perigosa a interpretação utópica da história (TILLICH, 2005, p. 788), por ser, numa palavra, uma "compreensão equivocada da providência histórica que busca a realização da história na própria história" (TILLICH, 2005, p. 273, grifo meu).

Por sua vez, tal gênese e crítica do conceito de utopia incide no processo que o modela como um gênero narrativo, cujas bases são relativamente bem delineadas na obra morusiana, sob dois aspectos centrais:

Embora a ideia de utopia não deva ser confundida com a ideia de perfeição, um de seus traços mais reconhecíveis é seu discurso especulativo sobre uma organização social inexistente que é melhor do que a sociedade real. Outra característica é que é centrado no ser humano, não contando com o acaso nem com a intervenção de forças externas divinas para impor ordem à sociedade. As sociedades utópicas são construídas por seres humanos e são destinadas a eles (VIEIRA, 2010, p. 7 - tradução nossa).

Ou seja, embora humanamente centrada, há uma suspeita moral-antropológica na base da literatura utópica, em função do que suas

A quem está iniciando estudos em Tillich, vale dizer que esse termo é elementar no quadro conceitual da teologia da cultura. Define a qualidade de se atribuir sentido incondicional a algo condicionado, forjando-se assim um "ídolo". Opõem-se, portanto, à noção tillichiana de símbolo, na medida em que este media a incondicionalidade de sentido em tensão crítica e criativa com a natureza condicionada da linguagem. É um termo correlato à noção de demônico, e em seu conjunto, são noções básicas do que poderíamos definir como uma teoria da religião e/ou da linguagem religiosa em Tillich.

6 A mesma leitura poderia dar lugar a uma eclesiologia crítica, a partir da autorrelação que a Igreja estabeleceu, ao longo da história, com o símbolo de Reino de Deus. 
narrativas geralmente destacam e se desenrolam em torno de "um conjunto rígido de leis" que justamente qualificam uma forma de sociedade como utópica, na medida em que estas regras "forçam os indivíduos a reprimir sua natureza instável e não confiável, colocando-a sob um manto social mais conveniente" (VIEIRA, 2010, p. 7 - tradução nossa).

Disso resulta dois destaques relativos a características da narrativa utópica: primeiro, a relação destas narrativas com a realidade, tanto crítica como eventualmente prescritiva; segundo, a dimensão ficcional da narrativa, que é determinada por este objetivo crítico-prescritivo, de modo que, para não perder o consentimento à ficção do/a leitora, o gênero, se não ainda inaugura, ao menos coloca bases para o que veio a ser a narrativa realista na literatura moderna.

Em sua apropriação iluminista, contudo, a literatura utópica flexibiliza e mesmo acaba perdendo seu elemento paradoxal de não-lugar/ bom-lugar, dando ocasião para um novo neologismo: euchronia. A visão evolucionista e positiva da história como dimensão de realização humana infinita remodela e consolida o gênero em novas bases:

Ao privilegiar a noção de tempo e oferecer uma visão de um futuro de felicidade, a euchronia adquiriu uma dimensão histórica. A história era agora concebida como um processo de aperfeiçoamento infinito e a utopia, no espírito da euchronia, era apresentada como uma representação sincrônica de um dos anéis na cadeia do progresso. Por meio desse processo, a sociedade imaginada se aproximou da realidade histórica vivida pelo utopista. Ao projetar a sociedade ideal no futuro, o discurso utópico enunciava uma lógica de causalidades que pressupunha que certas ações (nomeadamente as de natureza política) poderiam proporcionar as mudanças necessárias para a concretização da sociedade imaginada. Desse modo, as utopias se dinamizam e promovem a ideia de que o homem tem um papel a cumprir (VIEIRA, 2010, p. 9 - tradução nossa).

A relação dessa inflexão temporal na imaginação literária utópica, sintetizada na ideia de euchronia localizada no futuro, convida a uma análise da relação entre o conceito de kairos e utopia no pensamento de Tillich - basicamente porque é à luz do primeiro que o mesmo faz sua crítica ao segundo conceito. O que, nesse ponto, valeria destacar é que ao lançar o ideal de sociedade para o futuro, tal imaginação literária implica numa visão utópica de história. Neste caso, trata-se de uma 
visão de história marcadamente positiva, que rompe com o paradoxo que coloca o bom-lugar sob sua negação - como vimos na tradição renascentista humanista de Morus. A crítica de Tillich, ao relacionar kairos e utopia, vai nessa direção: ele destaca a qualidade idolátrica do que chamou de utopismo como uma implicação da racionalização da história, desde a qual perde-se de vista o potencial demônico da história (TILLICH, 1988, p. 109-110) - o que estaria posto sob ressalva se a atitude utópica se valesse mais da noção de kairos, tal como Tillich o compreende, do que de euchronia, conforme acima definido, como critério hermenêutico da história.

Descolada da referência espacial e focada na expectativa histórico-temporal, a literatura utópica iluminista e moderna não se demora para ganhar traços universalizantes. Não é, contudo, um processo homogêneo, face às diferentes e contraditórias maneiras que a modernidade - e suas narrativas utópico-colonialistas (SARGENT, 2010) - se estabelece nos diferentes contextos da Europa e do mundo. Em torno dessas diferenças é que o gênero utópico se diversifica em subgêneros narrativos, considerando o foco na crítica não apenas no modelo de uma sociedade com leis rígidas e eficazes, mas também nas condições efetivas de potencial humano para tal. É o que Fátima Vieira destaca na utopia satírica (subgênero que prevaleceu na literatura utópica inglesa no século XVIII), cujo foco está em lançar suspeitas e mesmo corrigir o espírito utopista - a exemplo de As viagens de Gulliver (1726), de Jonathan Swift, que se posicionava publicamente, a essa época, contrário ao progresso por razões tanto técnicas quanto espirituais. Nessa obra,

a atenção do leitor é de fato cativada pelos presumivelmente brilhantes mas na realidade muito tacanhos - esquemas de Gulliver para sobreviver nos mundos um tanto quanto tolos que ele visita. O resultado é que, no final das contas, é o mundo real que se valoriza e, assim, a dinâmica positiva típica da utopia se perde (VIEIRA, 2010, p. 16 - tradução nossa).

Tal ceticismo é a fonte do que veio a chamar-se distopia, ou anti-utopia e ainda utopia negativa, cujos traços se antevê em obras ainda do século XIX, como Frankstein ou o prometeu moderno, de Mary Shelley (1818), mas que ganha plena manifestação literária e se consolida como gênero, de forma substancial, no decorrer do século XX. 
O termo surge em um discurso de John Stuart Mill, em 1868, que chamava atenção: "se a utopia era comumente vista como "muito boa para ser praticável', então a distopia era 'muito ruim para ser praticável" (apud VIEIRA, 2010, p. 16). A palavra nasce, portanto, sintetizando uma atitude intelectual pré-existente, de traço conservador em relação às promessas do progresso e suas consequências especialmente no âmbito da moralidade, com base no receio quanto ao potencial de desgraça que o futuro também reservava - nesse caso, o socialismo. A partir daí, o ideário utópico sofre uma clivagem determinante. De um lado, permanece com traços humanistas e referência crítica à realidade no pensamento socialista; de outro lado, prevalece na literatura e pensamento alinhados com o progressismo liberal com um sentido negativo e conservador, como algo a ser evitado - abrindo caminho para a "virada distópica da utopia” (FERREIRA, 2015; HILÁRIO, 2013; MARQUES, 2014).

Esta virada incide tanto na literatura como na nova e promissora arte narrativa, o cinema ${ }^{7}$ - a ponto de confundir-se com a história deste. A profusão de obras que se valem do espírito da época, de desencanto e frustração frente às promessas da modernidade, se dividem entre obras que espelham mimeticamente essa realidade ao lado daquelas que o fazem de forma crítica, refratando à sociedade suas próprias narrativas da realidade. Ou seja, não se trata de uma simples oposição à utopia. Antes, o caráter negativo do não-lugar em relação ao bom-lugar é que extrapola na distopia, radicalizando especialmente a crítica ao potencial humano para a realização concreta de uma vida plausível em sentido não apenas técnico e objetivo, mas existencial e subjetivo.

Sob esse aspecto, vemos uma aproximação de Tillich com essa perspectiva, ao encetar sua crítica ao que chama de "pós-história" e utopias negativas, narrativas nas quais a "experiência do presente" projeta-se numa possibilidade de futuro em que "o poder autodestrutivo da humanidade venha a prevalecer e destrua a humanidade histórica", ou um futuro no qual o ser humano perca o potencial de

7 Entre os principais títulos da literatura distópica, é mais regra do que exceção a identificação de obras que, uma vez adaptadas para o cinema, se tornaram referência estética para a consolidação do gênero narrativo na sétima arte, por exemplo: Nós, de Yevgeny Zamyatin (publicado em 1924); Admirável Mundo Novo, de Aldous Huxley (1932), 1984, de George Orwell (1949); Fahrenheit 451, de Ray Bradbury (1953); Laranja Mecânica, de Anthony Burgess (1962) e ainda O caçador de androides, de Philip K. Dick (1968). 
transcender "a insatisfação com o que existe e, consequentemente, o impulso para o novo":

Neste estado, a raça humana seria semelhante àquilo que Nietzsche descreveu como o "último ser humano", ser humano que "conhece todas as coisas", porém não se interessa por coisa alguma; seria o estado de "bem-aventurança animal". As utopias negativas de nosso século, como Admirável Mundo Novo, antecipam - acertada ou erroneamente - este estágio evolutivo. (...) Estes e talvez ainda outros desdobramentos da humanidade pós-histórica devem ser considerados possíveis, e não devem ser confundidos com os símbolos do "fim da história" em seu sentido escatológico. (TILLICH, 2005, p. 745)

Essa crítica, por sua vez, já está presente no escrito seminal sobre a contribuição histórico-hermenêutica da noção de demônico (Das Dämonische Ein Beitrag zur Sinndeutung der Geschichte, de 1926), para a qual Tillich evoca a premissa de um elemento mítico em toda narrativa histórica, que é do que depende seu potencial autotranscendente do aqui e agora. Na medida que narrativas históricas se valem de uma visão utópica em sentido positivo e moderno, contudo, elas "enfraquecem o elemento mítico", retirando de sua descrição da finitude aquilo que aponta para um além de, que é a orientação à incondicionalidade de sentido. O que resulta disso é uma orientação "exclusivamente para sua realização neste mundo", na qual:

O mito é racionalmente achatado. As coisas históricas perdem sua transcendência, seu poder simbólico. A utopia ignora o fato do demônico como um elemento de toda a criação histórica. Ela imagina um mundo desdemonizado (entdämonisierte Welt) a partir desse mundo. Ela nada sabe sobre a dependência da humanidade em relação à natureza e sobre todos os entes sob a ambiguidade e a natureza não-essencial (TILLICH, 1988, p. 109-110 - tradução nossa) ${ }^{8}$.

8 Do original: "Der Mythos wird rational verflacht. Die historischen Dinge verlieren ihre Transzendenz, ihre Symbolkraft. Die Utopie übersieht die Tatsache des Dämonischen als Element aller geschichtlichen Schöpfung. Sie nimmt eine diesseitige, entdäimonisierte Welt in Aussicht. Sie weiß nichts von der Verbundenheit der Menschheit mit der Natur und allem Seienden unter der Zweideutigkeit und Wesenswidrigkeit". Agradeço a preciosa revisão desta tradução por Fábio H. de Abreu. 
Nesses termos, portanto, a profusão contemporânea de narrativas distópicas - com seus próprios desdobramentos em subgêneros e “ondas" (CLAEYS, 2010) - poderia ser analisada como uma irrupção deste elemento mítico-demônico na imaginação e consciência utópica, dando-se conta ela mesma de seus limites, desilusão e desespero, seja como sintoma ou como protesto a suas expressões idolátricas. Evidentemente, esse não seria um aspecto inequívoco na literatura e no cinema, mas um traço passível de ser identificado e interpretado a partir de um conjunto de obras.

\section{Conclusão}

Neste artigo, exploramos o campo de estudos da narrativa utópica visando uma relação analítica entre distopia e religião a partir da teologia da cultura de Paul Tillich. Vimos que a utopia, enquanto referência de pensamento e imaginação narrativa, deita raízes na cultura humanista-renascentista e confunde-se, numa significativa inflexão, com a visão moderna de mundo, forjando a própria ideia de cultura em bases utópicas. A crítica da apropriação moderna da imaginação utópica, por sua vez, demonstrou que nesta se perdeu um elemento crítico-negativo fundamental na obra germinal de Thomas Morus, desde a qual o autor desenvolve mais do que um modelo legal e moral de organização social, uma crítica à realidade social inglesa de sua época.

Em nossa análise, apontamos a hipótese de compreender que o potencial crítico à modernidade incide em narrativas utópicas contemporâneas desde uma "virada distópica", na qual identificamos elementos críticos correlacionados ao conceito de demônico, tal como proposto por Tillich. Para tal, recuperamos premissas importantes do conceito de história na obra de Tillich, enfatizando uma relação fundamental entre história e mito, desde a qual a descrição histórica da realidade permita realizar sua vocação autotranscendente, no sentido de apontar para uma experiência de mundo para além de si mesmo - em sentido crítico e criativo.

Nesses termos, a relação entre distopia e religião demarca uma perspectiva de estudo de narrativas literárias e cinematográficas, focada na análise de elementos mítico-demonicos expressos em suas representações e poéticas como sintoma e/ou "protesto" a perspectivas 
utópico-idolátricas. Embora caracterizadas por um repertório crítico-negativo, tais narrativas traduziriam se não uma atitude de esperança, ao menos o seu desejo.

\section{Referências}

ALMINO, João. A Utopia é um império (prefácio). In.: MORUS, Thomas. Utopia. Prefácio: João Almino. Tradução: Anah de Melo Franco. Brasília: Editora Universidade de Brasília: Instituto de Pesquisa de Relações Internacionais, 2004.

CLAEYS, Gregory. The origins of dystopia: Wells, Huxley and Orwell. In: CLAEYS, Gregory (Ed.). The Cambridge Companion to Utopian Literature. Cambridge: Cambridge University Press, 2010. p. 107-131.

FERREIRA, Vítor Vieira. Utopia e distopias no século XXI e pós-modernismo. Revista Papéis, Campo Grande, v. 19, n. 38, p. 64-82, 2015. Disponível em https://periodicos.ufms.br/index.php/papeis/article/view/2988/2406, acesso em 10/09/2021.

HILÁRIO, Leomir Cardoso. Teoria crítica e literatura: a distopia como ferramenta de análise radical da modernidade. Anuário de Literatura, Florianópolis, v.18, n. 2, p. 201-215, 2013. DOI: http://dx.doi.org/10.5007/2175-7917.2013v18n2p201, acesso em 10/09/2021.

MARQUES, Eduardo Marks. Da centralidade política à centralidade do corpo transumano: movimentos da terceira virada distópica na literatura. Anuário de Literatura, Florianópolis, v. 19, n. 1, p. 10-29, 2014. DOI: http://dx.doi. org/10.5007/2175-7917.2014v19n1p10, acesso em 10/09/2021.

MORUS, Thomas. Utopia. Tradução: Anah de Melo Franco. Brasília: Editora Universidade de Brasília: Instituto de Pesquisa de Relações Internacionais, 2004.

SARGENT, Lyman Tower. Colonial and postcolonial utopias. In.: CLAEYS, Gregory. The Cambridge Companion to Utopian Literature. Cambridge: Cambridge University Press, 2010, p. 200-222.

TILLICH, Paul. Das Dämonische Ein Beitrag zur Sinndeutung der Geschichte (1926). In.: SCHARLERNANN Robert P. (ed.). Paul Tillich Main Works. Hauptwerke: writings on religion. Religiöse Schriften. Volume 5. Berlin. New York: De Gruyter. Evangelisches Verlagswerk GmbH, 1988, p. 99-123.

TILLICH, Paul. Teologia sistemática. 5ed. Revista. Tradução: Getúlio Bertelli; Geraldo Korndörfer. Revisão: Enio Mueller. São Leopoldo: Sinodal. EST, 2005.

VIEIRA, Fátima. The concept of utopia. In.: CLAEYS, Gregory. The Cambridge Companion to Utopian Literature. Cambridge: Cambridge University Press, 2010, p. 3-28. 
YORAN, Hanan. Between Utopia and Dystopia: Erasmus, Thomas More, and the Humanist Republic of Letters. Lanham: Lexington Books, 2010.

Submetido em: 10-1-2022

Aceito em: 17-12022 